\title{
Micromechanisms of ductile fracturing of DH-36 steel plates under impulsive loads and influence of polyurea reinforcing
}

\author{
M. R. Amini · S. Nemat-Nasser
}

Received: 25 August 2009 / Accepted: 25 February 2010 / Published online: 20 April 2010

(C) The Author(s) 2010. This article is published with open access at Springerlink.com

\begin{abstract}
Micromechanisms of ductile fracturing of DH-36 steel plates subjected to blast-induced pressure loads are studied experimentally using specially designed dynamic testing facilities. The sample geometry is such that it undergoes controllable fracturing, generally initiated near its center and grows first circumferentially and then radially. Selected fractured samples are sectioned normal to the fracture surfaces, at various intervals along the length of the fracture which extends into the necked and finally to the uniformlydeformed material. The thickness profile of the sample at each cross section is analyzed using optical and scanning electron microscopy. In this manner, we have been able to examine the microstructural evolution that has taken place, from necking inception to fracture initiation and growth, leading to a better understanding of the underpinning mechanisms of the fracturing of this material. The observed ductile fracture involves void nucleation, and void growth and coalescence, creating dimpled fracture surfaces. The examination of the microstructure of the deformed steel samples also revealed that the microstructure does not change
\end{abstract}

M. R. Amini

Omnicell Inc., 1201 Charleston Road, Mountain View, CA 94093, USA

e-mail: mr_amini_2000@yahoo.com

S. Nemat-Nasser $(\varangle)$

Center of Excellence for Advanced Materials, Department of Mechanical and Aerospace Engineering, University of California, La Jolla, San Diego, CA 92093-0416, USA e-mail: sia@ucsd.edu significantly during the deformation and that there are no shearbands developing in and around the fracture zones. Based on the observed micro-scale deformation, a finite-element model was developed to further study the fracturing process, using a physics-based and experimentally-supported temperature- and rate-sensitive constitutive model for DH-36 steel. The finiteelement model was capable of predicting the fracture process of the steel plates rather well. Additional finiteelement simulations are performed to investigate the effect of the polyurea coating on the fracturing and fracture resistance of the plates. These also correlated well with the experimental results.

Keywords Micro-scale analysis · Polyurea-steel bilayer · Impulsive loads · Fractography

\section{Introduction}

Ductile fracture of steel structures has been the subject of extensive studies in the past few decades, both experimentally and numerically. DH-36 steel is a high strength structural steel used in naval and other structural applications (i.e., as ship hulls). As a plate structure, it may be subjected to underwater impulsive loads. In a previous study (Amini et al. 2010a), the response of monolithic steel and bilayer steel-polyurea plates to impulsive loads is studied, focusing on the effect of polyurea on the performance of the steel plates using a direct impactinduced pressure-pulse experimental technique. To further understand the process of deformation and failure of 
the steel plates and the effect of polyurea on their performance, a micro-scale study is performed, using optical microscopy and scanning electron microscopy (SEM), focusing on the fracture pattern and the mechanism of failure. These experimental studies are paralleled with numerical modeling of the entire failure process.

Steel exhibits a wide variety of failure mechanisms depending on the environmental conditions, the microstructure of the steel, and the loading conditions. Cleavage fracture and ductile fracture are the two main fracture modes observed in failed steel structures. Two ductile fracture mechanisms have been identified in high strength steels, depending on load triaxiality. First is a void coalescence process in which relatively equiaxed voids grow under positive triaxial loads to coalesce, leading to failure. Second is a void-sheer mechanism in which failure occurs by a micro-void shear localization process under shear loading (zero or negative load triaxiality).

The nucleation, growth, and coalescence of voids under positive triaxial loads have been studied extensively by many researchers (Hammi and Horstemeyer 2007; Tvergaard and Hutchinson 2002; Horstemeyer and Gokhale 1999). McClintock (1968) performed the first theoretical analysis of void growth by studying the growth of cylindrical holes of elliptical cross section with axes parallel to the principal directions of the applied stress. Rice and Tracey (1969) studied the growth of a spherical void under a general remote stress field. They found that, for any remote strain-rate field, the enlargement of spherical voids is amplified by a factor of an exponential function of the stress triaxiality. McVeigha et al. (2007) studied the micro-void shear localization softening mechanism and modeled the process at the scale of the secondary particles under pure shear loading conditions using the commercially available finite-element software ABAQUS. A comprehensive review of the past research on ductile fracture of solids is presented by Curran et al. (1987) and Garrison and Moody (1987).

In a recent study, Nemat-Nasser and Guo (2003) examined the microstructure of DH-36 samples under high strain-rate loads over a wide range of temperatures.
They found that the microstructural evolution of the material is not very sensitive to changes in strain rates and temperatures.

In this study, the microstructural evolution of impulsively loaded DH-36 steel plates in direct impact experiments is closely examined. The microstructures of several deformed and undeformed samples are examined by optical microscope and scanning electron microscope, seeking to understand the fracture pattern and the mechanism of failure. Finite-element models are developed based on the micro-scale examination of the failed samples. The numerical models predict the experimentally-observed fracture patterns. In addition a simulation is performed to study the void growth process. Finally, the effect of polyurea coating on the fracture resistance of the steel plates is numerically simulated.

\section{Materials and samples}

\subsection{DH-36 steel microstructure}

The chemical composition of high strength low alloy DH-36 structural steel is given in Table 1, taken from Nemat-Nasser and Guo (2003). This steel is a hypoeutectoid alloy ( $0.14 \mathrm{wt} \%$ carbon) with ferrite and pearlite as the prime constituents. Using the lever rule it can be shown that the volume fractions of pearlite and ferrite are 17.5 and $82.5 \%$, respectively. The relative amount of pearlite makes this alloy more rust resistant compared to other carbon steel alloys. Figures 1 and 2 show the microstructure of an undeformed DH36 steel plate sample perpendicular to and along the rolling direction. In these figures, white regions are ferrite and black regions are pearlite. Ferrite or alpha iron $(\alpha-\mathrm{Fe})$ is a body centered cubic (BCC) crystal and has a lower strength and hardness but higher plasticity and toughness, relative to pearlite that has a two-phase lamellar structure, composed of alternating layers of $\alpha-\mathrm{Fe}(88 \mathrm{wt} \%)$ and cementite or iron carbide (12 wt $\%)$, which accounts for the higher strength and hardness and lower plasticity and toughness.

Table 1 Major alloy content of DH-36 steel (\%) reported by Nemat-Nasser and Guo (2003)

\begin{tabular}{|c|c|c|c|c|c|c|c|c|c|c|c|}
\hline $\mathrm{C}$ & $\mathrm{Mn}$ & $\mathrm{Cu}$ & $\mathrm{Si}$ & $\mathrm{Cr}$ & Mo & $\mathrm{V}$ & $\mathrm{Ti}$ & $\mathrm{Al}$ & $\mathrm{Nb}$ & $\mathrm{P}$ & $\mathrm{S}$ \\
\hline 0.14 & 1.37 & 0.14 & 0.22 & 0.08 & 0.03 & 0.001 & 0.003 & 0.017 & 0.03 & 0.007 & 0.001 \\
\hline
\end{tabular}




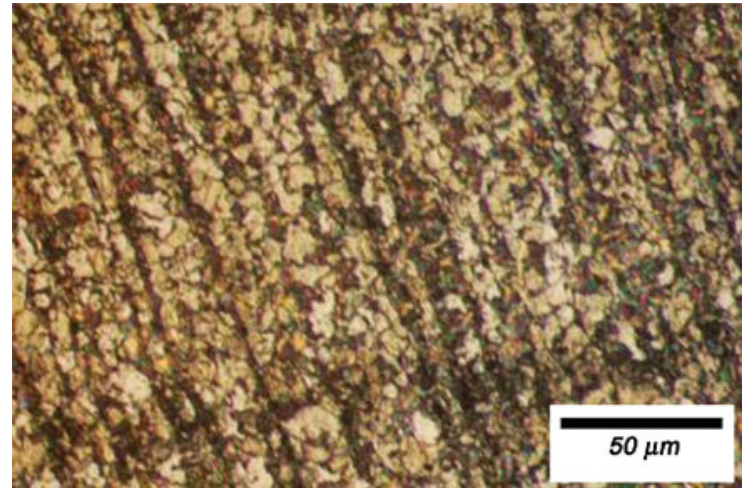

Fig. 1 DH-36 steel microstructure perpendicular to the rolling direction obtained by optical microscope at $\times 400$

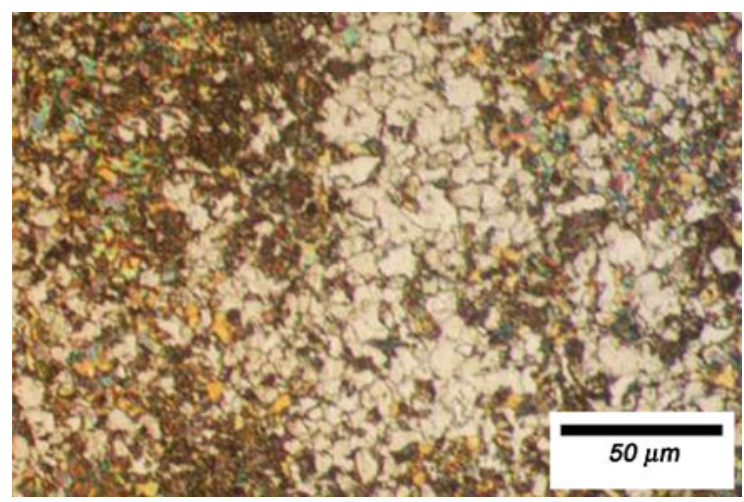

Fig. 2 DH-36 steel microstructure in the rolling direction obtained by optical microscope at $\times 400$

DH-36 is microalloyed by grain refining elements such as aluminum and vanadium.

\subsection{Sample specification}

The plates are EDM machined from a DH-36 steel base plate. Figure 3 shows a DH-36 monolithic sample

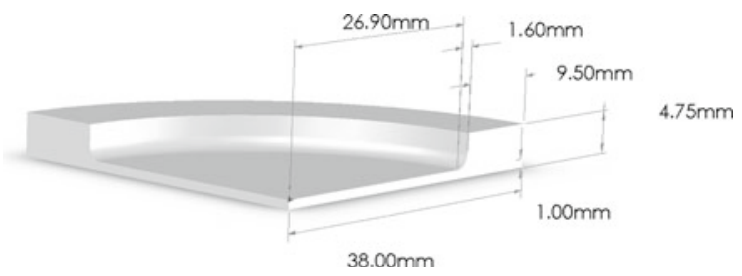

Fig. 3 Nominal dimensions of the monolithic steel plate (quarter of plate)

and its nominal dimensions. The plates have a nominal thickness of $1 \mathrm{~mm}$ over a $54 \mathrm{~mm}$ central gauge section and a nominal outer diameter of $76 \mathrm{~mm}$ with an edge thickness of $4.5 \mathrm{~mm}$. The gauge section is formed by a $57 \mathrm{~mm}$ diameter counterbore $3.5 \mathrm{~mm}$ deep with a $1.5 \mathrm{~mm}$ radius at the bottom.

\section{Experiments and specimen preparation}

\subsection{Experimental setup}

The dynamic loading of the plates are performed at UCSD's CEAM gas gun facilities using a direct impact-induced pressure-pulse experimental setup. In this setup, an aluminum projectile of known mass is propelled by a gas gun at a controlled velocity toward an impedance-matched piston that loads a confined soft polyurethane or water medium. The medium in turn loads the plate that rests on a cylindrical step (support) within a confining cylinder. The load is transferred from the support to a 3-inch Hopkinson output bar. The velocity of the projectile is recorded by velocity sensors placed at the end of the gas gun muzzle. The detailed description of the experimental setup and the results are presented in Amini et al. (2010a). The details of the experimental conditions of the samples used in this study are presented in Table 2.

Table 2 Conditions of the selected direct pressure-pulse experiments

\begin{tabular}{|c|c|c|c|c|c|c|c|}
\hline \multicolumn{6}{|c|}{ Specimen } & \multicolumn{2}{|l|}{ Projectile } \\
\hline \multirow[t]{2}{*}{ Test } & \multirow[t]{2}{*}{ Plate type } & \multirow[t]{2}{*}{ Poylurea cast } & \multicolumn{2}{|c|}{ Thickness (mm) } & \multirow[t]{2}{*}{ Loading device } & \multirow[t]{2}{*}{ Mass (g) } & \multirow[t]{2}{*}{ Velocity $(\mathrm{m} / \mathrm{s})$} \\
\hline & & & Steel & Polyurea & & & \\
\hline S-117X & Monolithic & N/A & 1.02 & N/A & Water & 1685.4 & 40.8 \\
\hline SP-97 & Bilayer & Front face & 1.00 & 3.75 & Polyurethane & 831.8 & 64.0 \\
\hline S-240 & Monolithic & N/A & 1.03 & N/A & Polyurethane & 1685.4 & 51.4 \\
\hline SP-240 & Bilayer & Back face & 1.02 & 3.75 & Polyurethane & 1685.4 & 51.1 \\
\hline
\end{tabular}




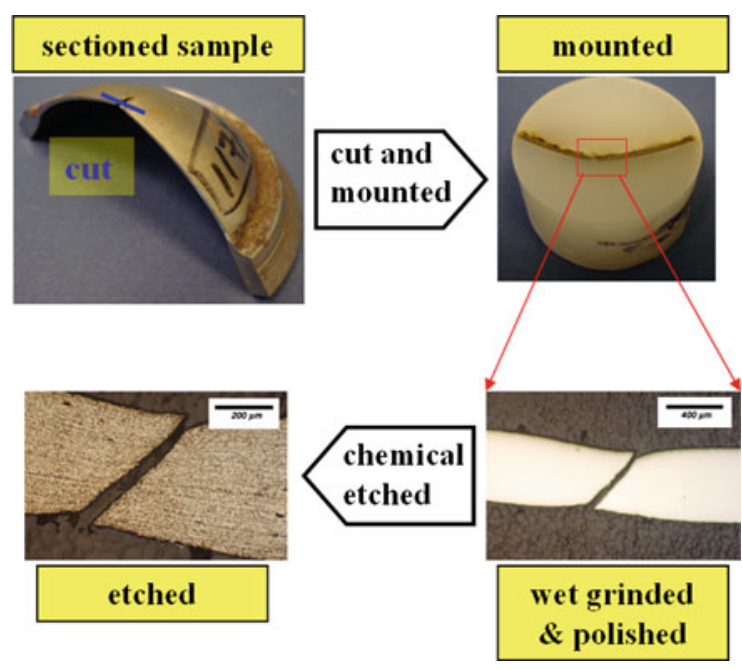

Fig. 4 The sequence of specimen preparation, involving cutting, mounting, wet grinding, polishing, and etching to reveal the microstructural constituents

\subsection{Specimen preparation for optical microscopy}

To examine the microstructure of the undeformed and deformed samples, selected samples are sectioned, and mounted into an epoxy, using a Teflon mold. The mounted samples are then wet ground, polished and etched. The wet grinding is performed in three steps using 500, 1,200 and 4,000 grit paper, respectively. The specimen is polished next with 3 and $1 \mu \mathrm{m}$ diameter diamond particles on a napless cloth to produce a scratch-free mirror finish. To see the grain boundaries and the microstructural constituents, the specimen is etched with Nital, a mixture of $98 \mathrm{ml}$ ethyl alcohol and $2 \mathrm{ml} \mathrm{H}_{2} \mathrm{NO}_{3}$. Figure 4 summarizes the procedure described above.

\section{Micro-scale analysis}

\subsection{Microscopy: necking and fracturing process}

In this section the results of the microscopy of selected tested samples are reported. Two marginally failed samples, SP-97 and S-117X, and a severely failed sample, SP-246, are prepared for microscopy. Plates SP-97 and S-117X are shown in Fig. 5 Several parallel sections, along the direction normal to the crack openings are made to map the sequence of necking initiation and growth that leads to the sample fracturing.

It is known that when ductile solids are deformed sufficiently into the plastic regime, a smooth and continuously varying deformation pattern gives way to highly localized deformation in the form of a neck. Visual inspection of the highly deformed steel plates, tested in the direct pressure-pulse experiments, reveals that multiple parallel necks form at the central region of the plates. Figure 6 shows a SEM photo of a section from plate SP-97.

As the deformation localizes and leads to a necked region, voids form around some brittle inclusions and second phase particles (e.g., titanium nitrides), either by cracking of the particles, or by decohesion at the particle/matrix interface (Rice 1976). The void growth ceased once a highly localized deformed region is developed between adjacent voids. Within these deformed regions, a number of micro-voids are formed, which then grow with the plastic deformation and link up to create micro-necks. The micro-necks then extend and lead to a ductile fracture surface with a highly dimpled appearance and final atomic scale rupture of the plate. The same process of failure initiation has been
Fig. 5 Top view of the marginally failed samples, SP-97 and S-117X, selected for microscopy. The samples are cut normal to the crack direction to study their fracturing pattern
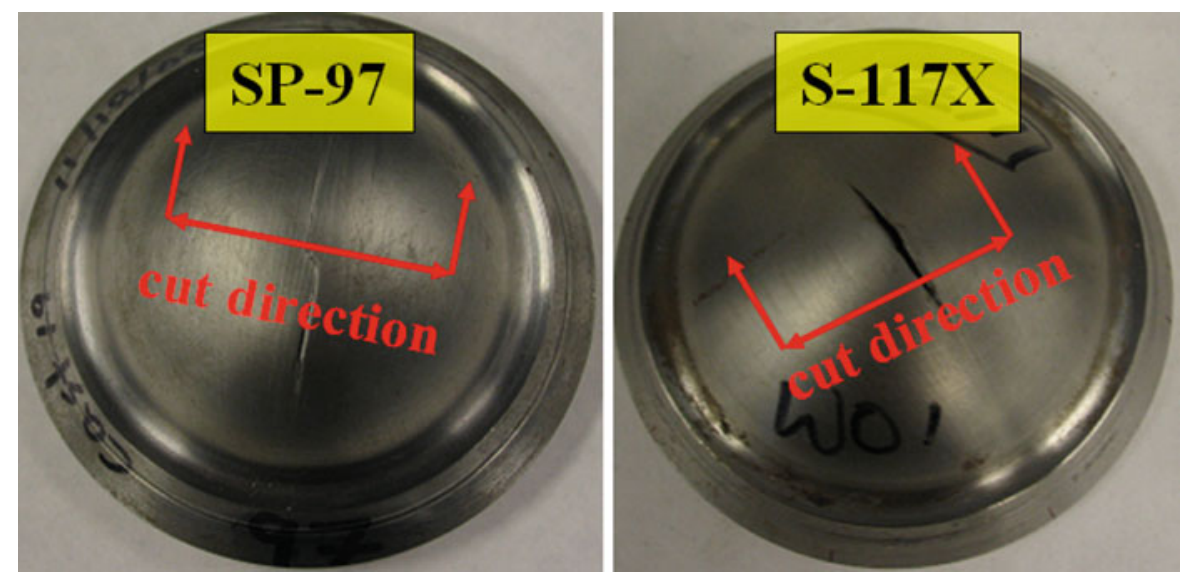
Fig. 6 SEM photo of the cross section of sample SP-97 at the crack tip.

Multiple necks are detected in this photo
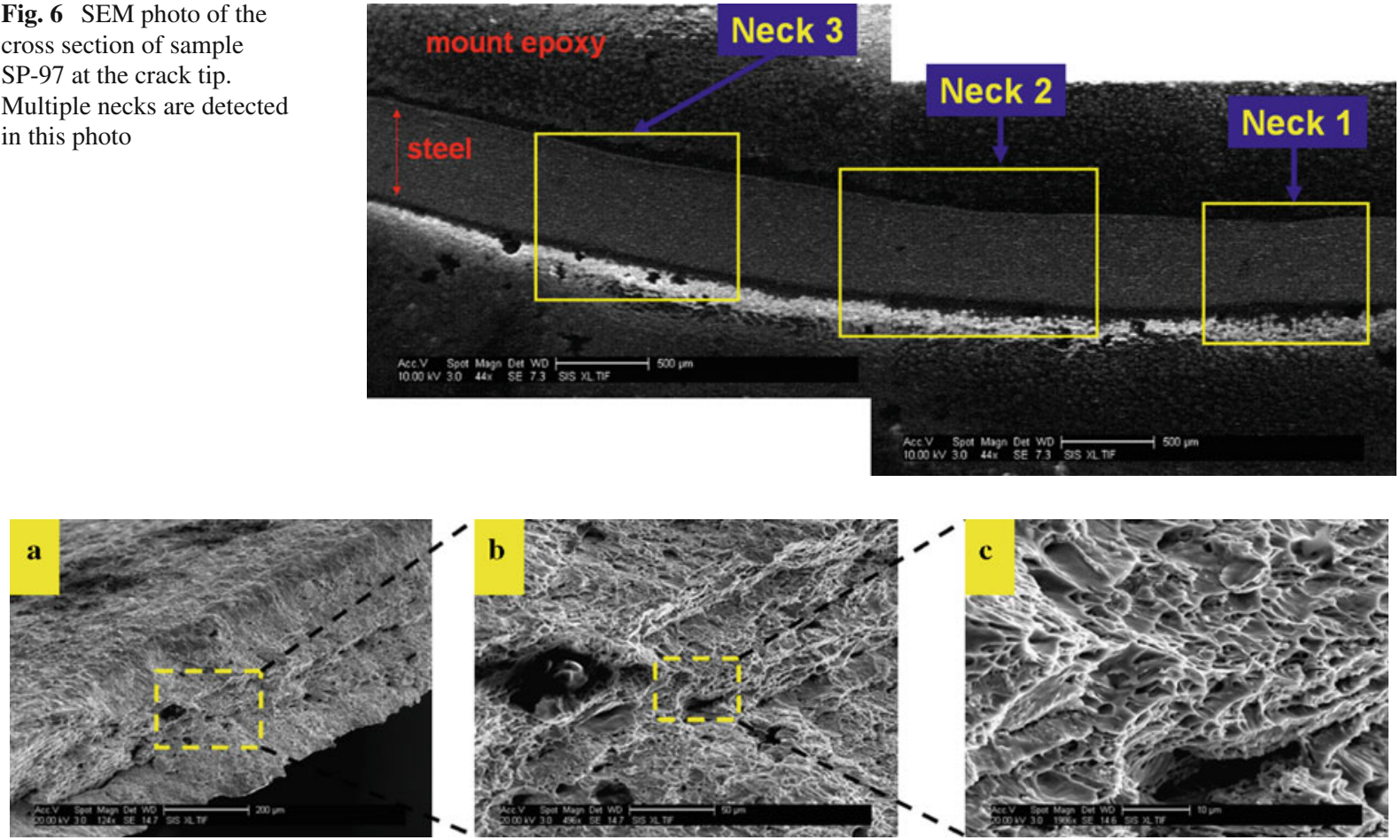

Fig. 7 SEM fractographs of the failed sample, S-117X: a, b primary voids on the fracture surface, and $\mathbf{c}$ micro-voids producing a highly dimpled appearance
Fig. 8 SEM fractographs of the failed sample, SP-246, at several levels of magnification, showing the dimple structure of the fracture surface

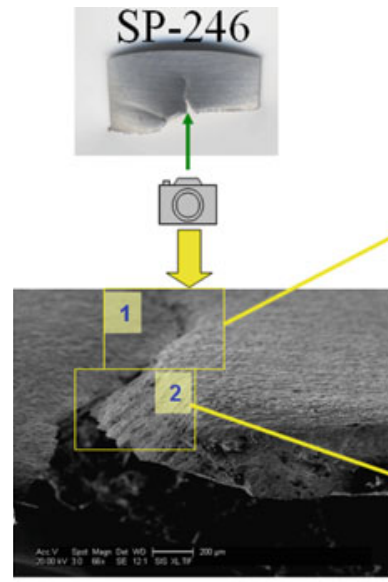

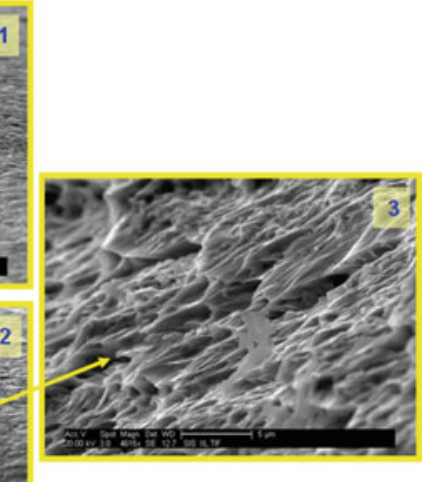

sample SP-246, at various magnifications. Figure 9 also shows several micrographs of plate $\mathrm{S}-117 \mathrm{X}$ at different magnifications, obtained by optical microscopy. These micrographs reveal two facts: first that microvoids are present on the fracture surface, and second that no shear bands are formed within the regions adjacent to the fracture surface. It is also noted that the reported by Cox and Low (1974) for high strength AISI4340 steel. Figure 7 shows several SEM fractographs of steel plate S-117X. The diameter of the primary voids in Fig. $7 \mathrm{a}$ and $\mathrm{b}$ range from 5 to $50 \mu \mathrm{m}$. On the other hand, the diameter of the micro-voids shown in Fig. $7 \mathrm{c}$ is less than $1 \mu \mathrm{m}$. Figure 8 shows several views of the dimpled fracture surface of severely failed 
Fig. 9 Several SEM micrographs of monolithic steel plate S-117X at different magnifications: a cross section of the sample showing the two fracture surfaces, $\mathbf{b}$ micro-voids are clear on the fracture surface, and $\mathbf{c}, \mathbf{d}$ no shear band can be detected adjacent to the fracture surface

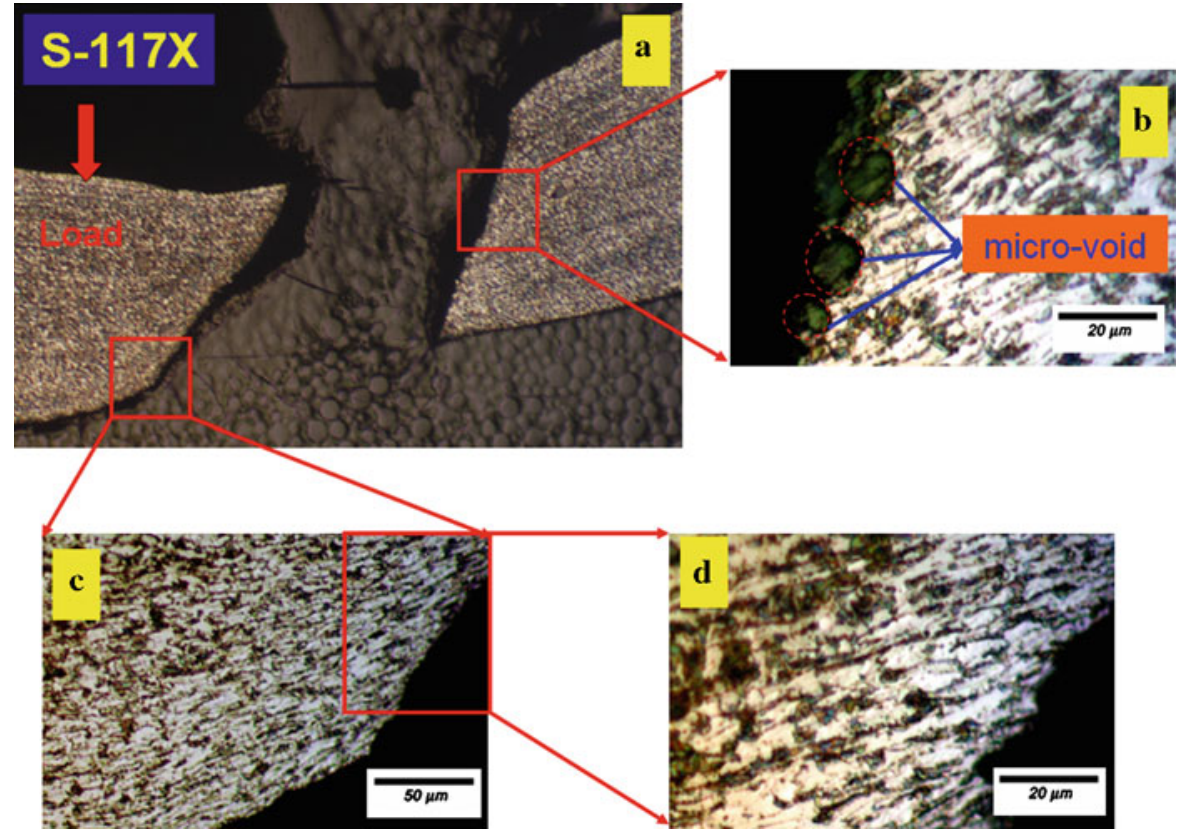

microstructure of the DH-36 steel does not seem to undergo any remarkable changes due to these large plastic deformations.

\subsection{Finite-element setup}

To understand the failure process of the plates under impulsive loads, a 3-dimensional finite-element model is developed using the commercially available code, LS-DYNA. The model geometry is based on a micrograph of plate SP-97 at the necked region. Figure 10 shows the micrograph (top of figure) with the dimensions of the plate at its necked region, and the dimensions of the finite-element model with its spatial discretization (bottom of figure). The plate is modeled using eight-node brick elements with one integration point; see LS-DYNA theoretical manual LSDYNA (1998). To model the plain-strain condition, one element is used in the $Z$-direction and all the nodes are restricted to allow movement only in the $X$ - and $Y$-direction. To model the deformation caused by the impulsive loads, the nodes on the left side of the model are moved at a constant velocity of $1.3 \mathrm{~m} / \mathrm{s}$ in the negative $X$-direction, and the nodes on the right side of the model are rotated at a constant angular velocity of $872 \mathrm{Rad} / \mathrm{s}$ about the $Z$-axis; see Fig. 10. This imposed deformation is based on the results of a full-scale simulation of the plate in the direction of the impulse in the experiment, as reported in Amini et al. (2010b). The boundary and initial conditions are imposed on the model as if the plate is loaded on its upper surface (Fig. 10, bottom), which is hence the load-receiving face (front face).

To model the steel plate, the physics-based (PB) model, developed by Nemat-Nasser and Guo (2003) for DH-36 steel, is implemented into LS-DYNA through a user-defined material subroutine in FORTRAN. This PB model expresses the flow stress (effective stress), $\tau$, as a function of temperature, $T$, effective plastic strain, $\gamma$, and effective plastic strain rate, $\dot{\gamma}$, as

$$
\begin{aligned}
\tau= & 70+750 \gamma^{0.25}+1,500 \\
& \times\left\{1-\left[-6.6 \times 10^{-5} T\left(\ln \frac{\dot{\gamma}}{2 \times 10^{10}}\right)\right]^{\frac{1}{2}}\right\},
\end{aligned}
$$

for $T \leq T_{c}$, where the stress is in MPa and $T$ is in degrees Kelvin. On the other hand, for $T \geq T_{c}$, we use $\tau=70+750 \gamma^{0.25}$,

where $T_{c}=\left[-6.6 \times 10^{-5}\left(\ln \frac{\dot{\gamma}}{2 \times 10^{10}}\right)\right]^{-1}$. In addition, a failure model is implemented into LS-DYNA though a user-defined subroutine. In this model, the fracture is assumed to occur in any element whose accumulated effective plastic strain, $\gamma$, has reached a critical value, $\gamma_{f}$. The element is then eliminated. The purpose of modeling failure is to understand the failure 
Fig. 10 Micrograph of sample SP-97 at the necked region with indicated dimensions (top). The spatial discritization for finite-element modeling, developed based on the micrographs with the indicated dimensions and boundary conditions (bottom)
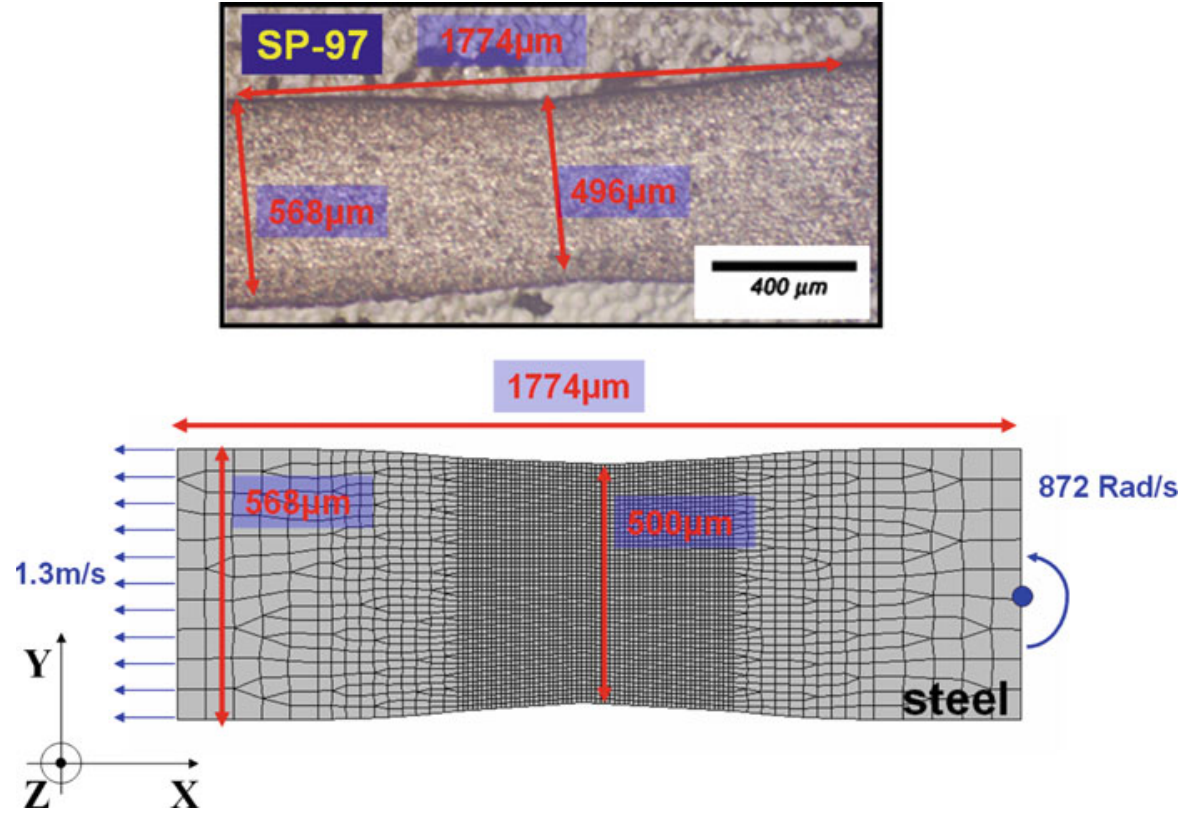

process, so the critical effective plastic strain value has to be estimated. As is discussed in Sect. 4.4, experimental observations seem to suggest a value of $\gamma_{f} \simeq 0.6$ just immediately before failure.

\subsection{Numerical predictions}

\subsubsection{Failure initiation}

Figure 11 shows the results of the finite-element predictions of the deformation and failure of the necked steel plate. The figure shows the time variation of the effective plastic strain contours of the plate. The numerical model suggests that the failure initiates from the back face at the center of the neck and then propagates to the front face along the fracture line at a $60^{\circ}$ angle with respect to the plate midplane, until the plate fails completely. The failure is such that the neck on the front face is on one side of the fracture line while the fracture line passes though the center of the neck on the back face. This prediction is confirmed by examination of the failed samples, SP-97 and S-117X; see Fig. 12. To be consistent with the finite-element models, the micrographs are oriented such that the plates are loaded from the top. Figure 13 shows the effective plastic strain time variation of two elements along the fracture line, one at the back face and the other on the front face. When the effective plastic strain of the element on the back
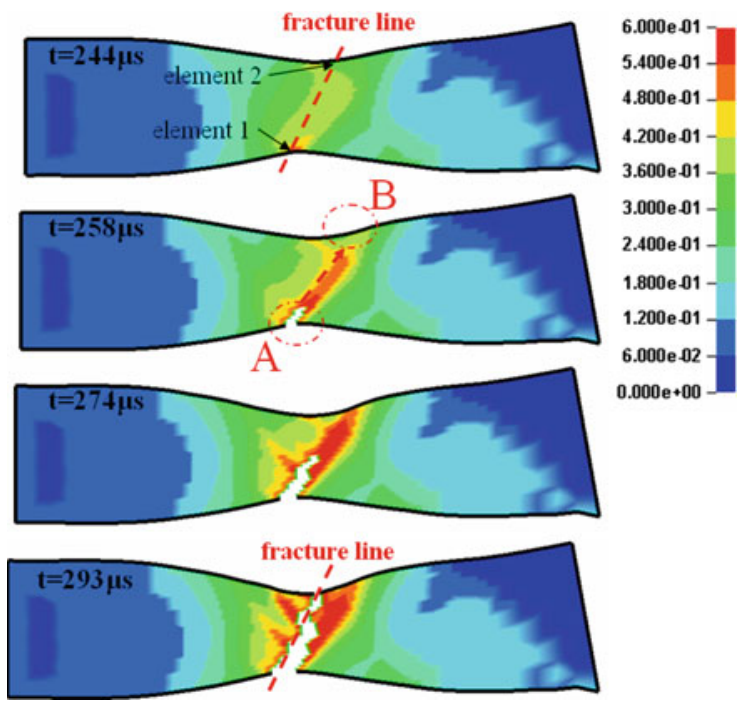

Fig. 11 The time variation of the effective plastic strain contours of the plat at indicated instances. The numerical model predicts that the failure initiates from the back face at the center of the neck and then propagates to the front face along the fracture line at about $60^{\circ}$ angle with respect to the plate's midplane

face is 0.65 at $\mathrm{t}=250 \mu \mathrm{s}$, the effective plastic strain of the element on the front face is 0.4 which is $38 \%$ less than that on the back face. Comparison of the micrographs and finite-element model results reveals that the finite-element model is able to predict the failure process. Note that the above results apply only to the steel 
Fig. 12 Micrographs of samples SP-97 and S-117X at the fracture zone
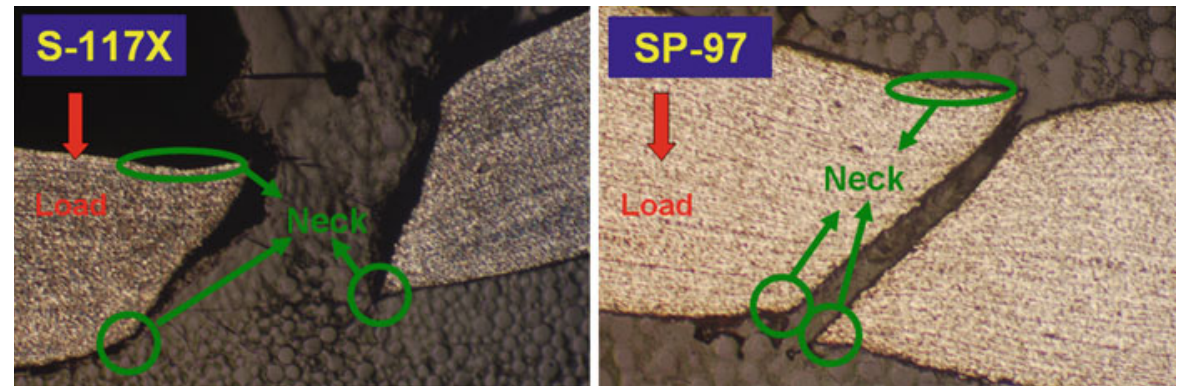

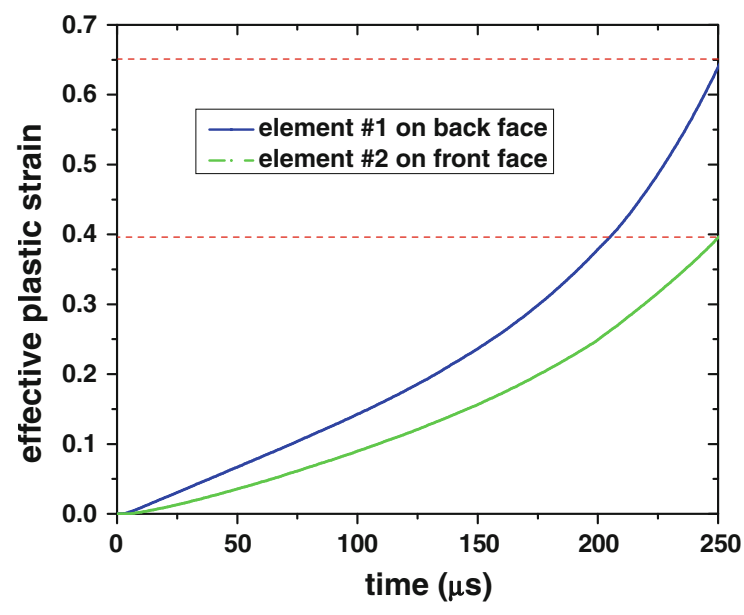

Fig. 13 Finite-element model prediction of effective plastic strain history of two elements along the fracture line, one on the back face and the other on the front face

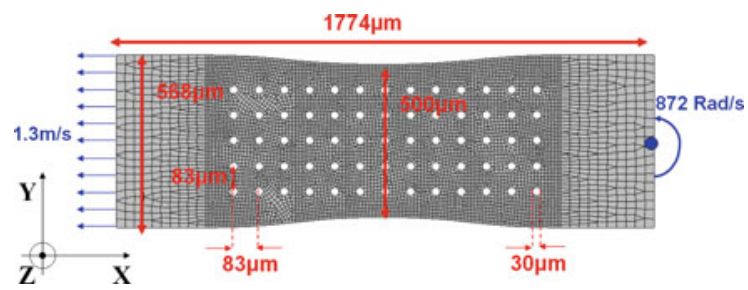

Fig. 14 Spatial discritization of the finite-element model of void growth with indicated dimensions and boundary conditions

plate without polyurea coating. When polyurea is cast on the back face, the strain is maximum at the front (not the back) face of the steel plate (see Fig. 17, discussed below).

\subsubsection{Void growth}

Ductile fracture nucleation in steel alloys involves decohesion of an embedded particle from the surrounding matrix or particle fracture (Rice 1976). In this high
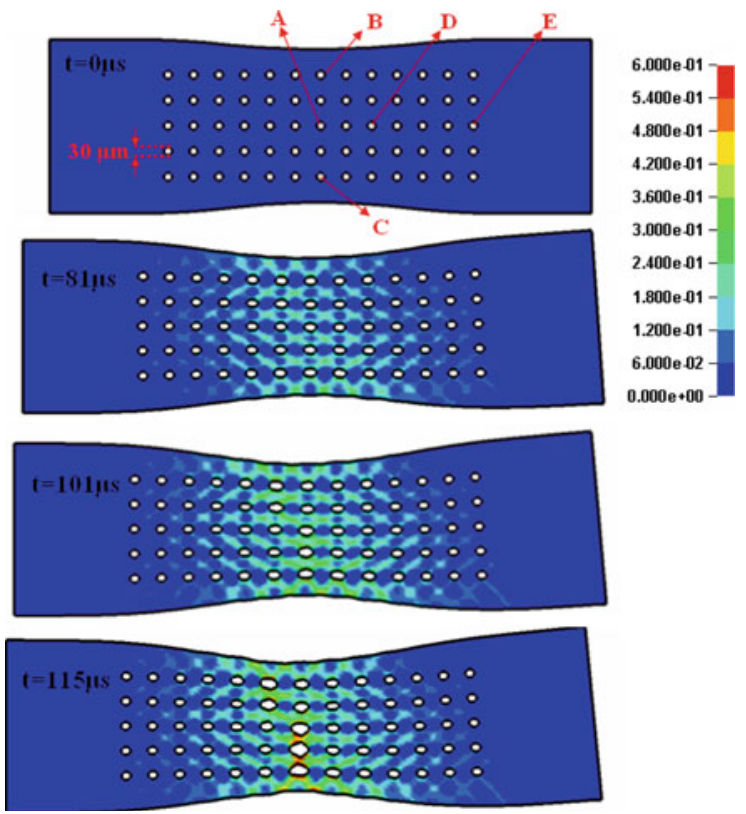

Fig. 15 A sequence of photos, showing the process of void growth and the corresponding effective plastic strain contours in the neck region of the steel plate

strength steel, the embedded particles are generally primary particles (e.g. titanium nitrides) on the order of several micrometers and secondary particles (e.g. carbides and manganese) on the order of several nanometers. A finite-element simulation is performed to study the growth of primary voids in the neck region. Figure 14 shows the initial distribution of the voids, the dimensions and the spatial discretization of the finiteelement model. The initial radius of the voids is $15 \mu \mathrm{m}$. The impulsive load is modeled by applying the same initial and boundary conditions explained in the pervious section. Figure 15 shows the time variation of the effective plastic strain contours of the model. The voids grow as the deformation proceeds until the strain localization bands are formed that in turn promote the 


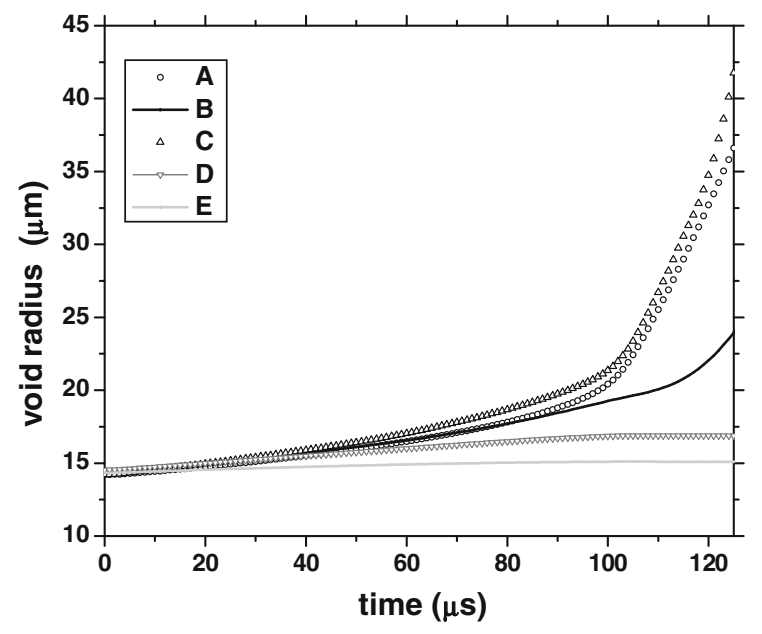

Fig. 16 Time variation of the void radius for selected voids

nucleation and growth of micro-voids, as also pointed out by Bandstra and Koss (2004) and Bandstra et al. (1998). They used finite-element micro-mechanical modeling to show that the strain localization arising between larger voids in HY-100 steel is sufficient to drive the nucleation of micro-voids from secondary particles.

To further understand the void growth in the neck region the radii of the selected voids are plotted as a function of time; see Fig. 16. This comparison of the time variation of the void radius reveals two facts. First that the voids at the center of the neck have a greater growth rate compared to the voids that are further away from the neck. Second that the voids that are close to the back face have a greater growth rate compared to the voids that are close to the front face. The study of the void growth in the neck model reveals that the voids at the center of the neck on the back face have a greater growth rate compared to the other voids.

\subsubsection{Effect of polyurea coating}

Two simulations are performed to study the effect of polyurea coating on the fracture resistance of the steel plates in the neck region and the performances are compared to the monolithic steel plate. In the first simulation a $600 \mu \mathrm{m}$ polyurea layer is present on the backface of the steel plate and in the second model a $600 \mu \mathrm{m}$ polyurea layer is present on its front face. Figure 17 shows the spatial discretization of the three finiteelement models: monolithic steel plate $(\mathrm{M})$, bilayer plate with polyurea on the back face (BB) and bilayer plate with polyurea on the front face (BF). The polyurea layer is modeled using eight-node brick elements with one integration point. An experimentally-based temperature-, rate-, and pressure-sensitive constitutive model for polyurea, developed and implemented by Amirkhizi et al. (2006), has been used to model the polyurea. The monolithic steel plate model has the same dimensions as the one shown in Fig. 10. In addition, the models use the same initial and boundary conditions explained in the pervious section. For each model, two elements, one on the front face and the other on the back face at the center of the neck region of the steel layer are selected. The time variations of the effective plastic strain of these elements are compared in Fig. 18 for each configuration (i.e. M, BB, and $\mathrm{BF})$. It is concluded that the effective plastic strain of the elements on the back face of the monolithic plate (M) and bilayer plate with polyurea on the front face (BF) is higher than that of the elements on the front face. However and remarkably, this is reversed for the
Fig. 17 Spatial discritization of the three plate configurations: monolithic plate $(M)$, bilayer plate with polyurea on the front face $(B F)$ and bilayer plate with polyurea on the back face $(B B)$

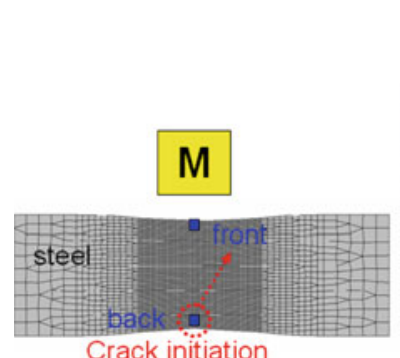

Crack initiation
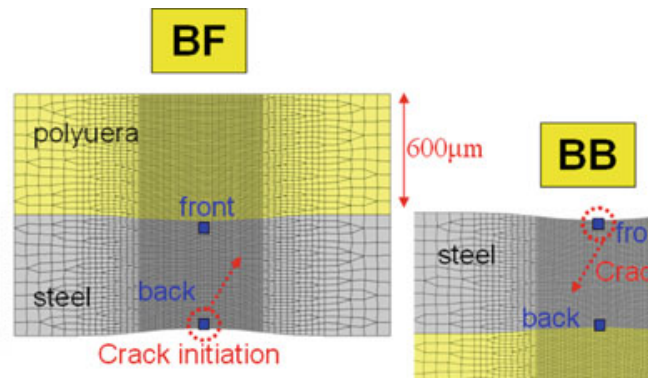

polyuera 


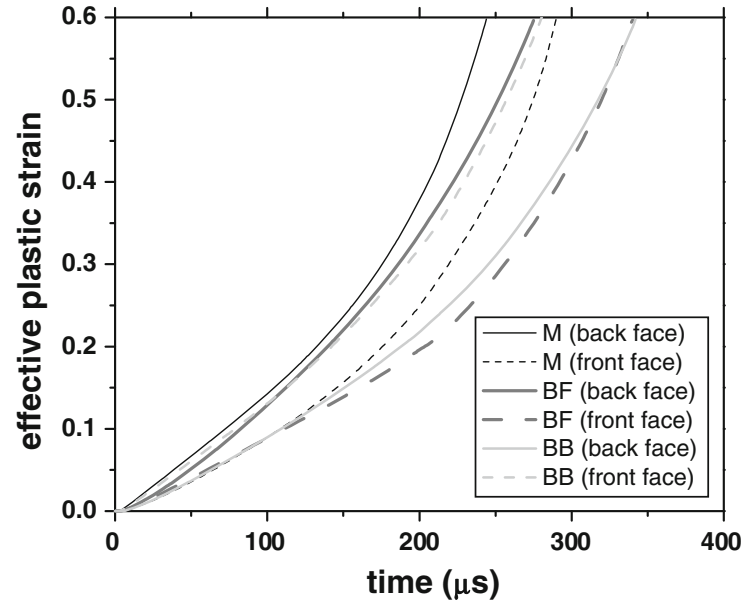

Fig. 18 Time variation of the effective plastic strain at the center of the neck, on the back face (back face) and front face (front face) for three plate configurations: monolithic plate $(M)$, bilayer plate with polyurea on the front face $(B F)$ and bilayer plate with polyurea on the back face $(B B)$

bilayer plate with a polyurea on the back face (BB), where the effective plastic strain is greater at the element on the front face of the steel plate. In addition, the results reveal that the presence of polyurea layer either on the front face or back face retards the neck development. This has been also pointed out by Xue and Hutchinson (2007). Among the three configurations, the bilayer plate with polyurea on the back face (i.e. BB) has a superior performance over the other two configurations.

\subsubsection{Fracturing of monolithic plate}

We have also simulated the entire process of failure initiation and crack growth for a steel sample without polyurea. In the corresponding finite-element calculation, when the effective plastic strain of an element reached a critical value of 0.60 , that element was simply eliminated. Figure 19 shows the resulting fracturing sequence. It initiates by the formation of a hoop crack near the center of the plate, producing four radial cracks within $300 \mathrm{~ms}$. These radial cracks then grow as shown in Fig. 19 (F-4)-(F-7), and finally leading to tangential cracks; see Fig. 19 (F-8)-(F-12). Figure 20 shows the location of the maximum effective plastic strain before crack initiation, and compares an actually failed sample (bottom, left) with the associated simulation result (top, right).

\subsection{Failure criterion}

Figure 21 shows the observed thickness variation in a neck region for SP-97. With $t_{0}$ being the initial
Fig. 19 Time variation of failure process, indicating hoop crack initiation, radial crack growth, and finally tangential cracking
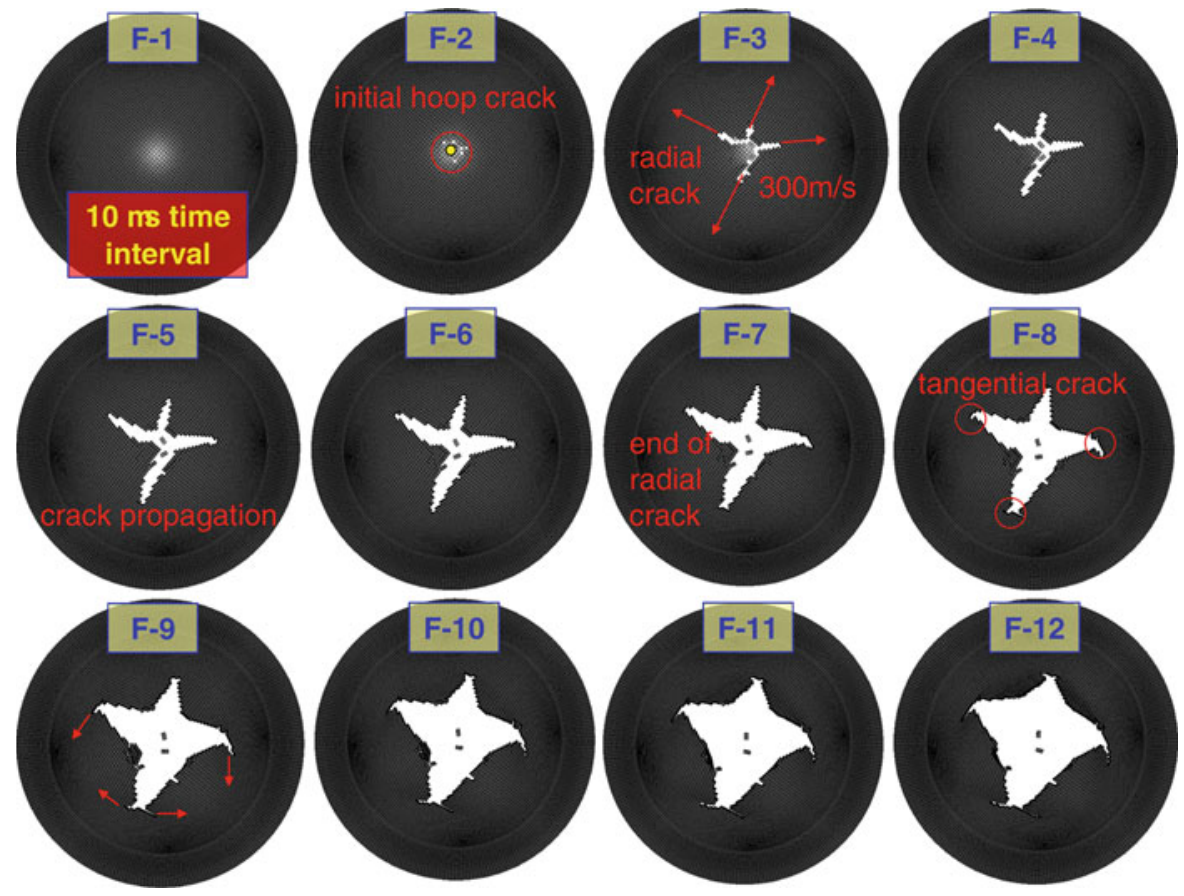


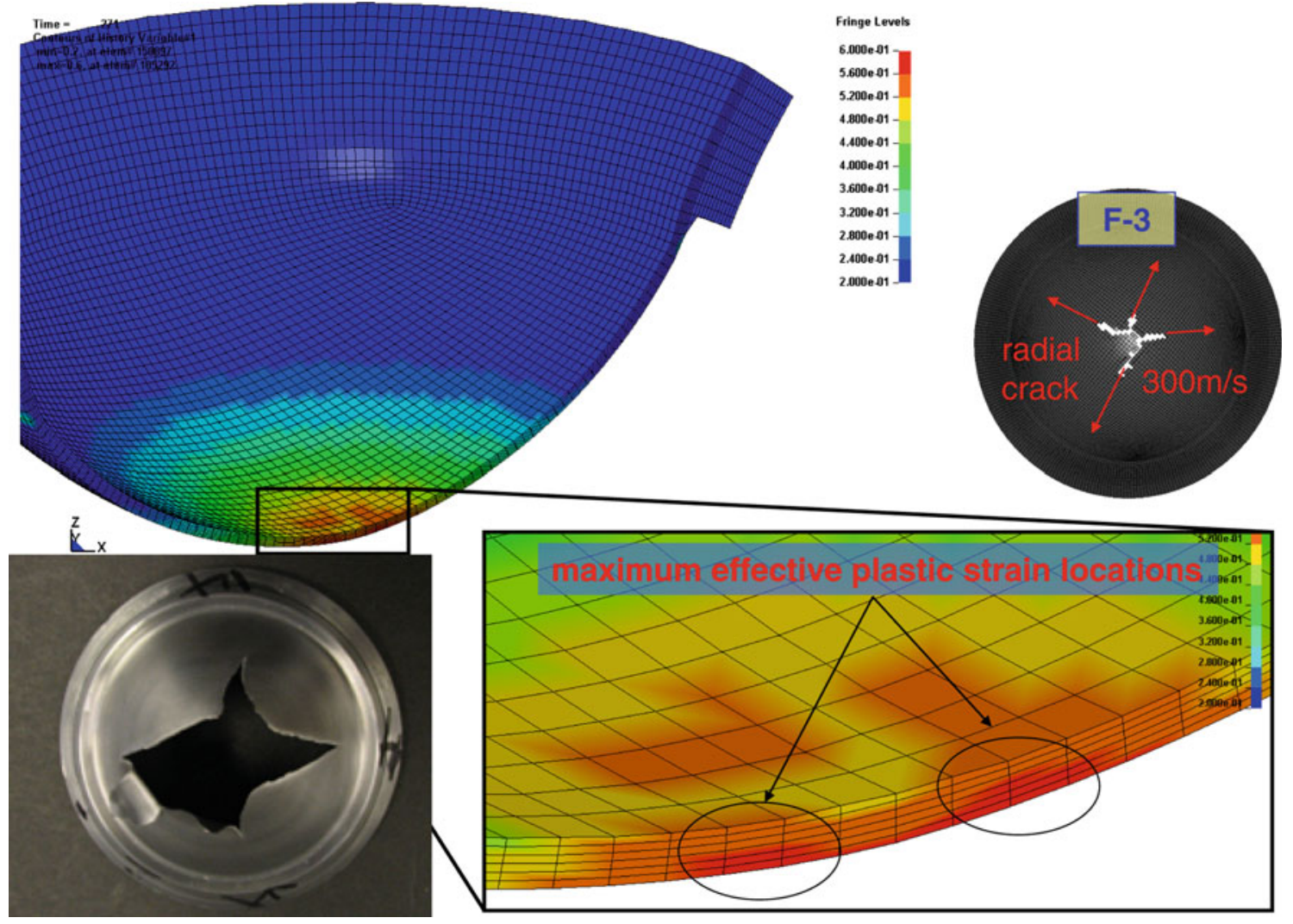

Fig. 20 Location of the maximum plastic strain (bottom, right), close but slightly away from the center of the plate, $300 \mathrm{~ms}$ after deformation initiation, and an actually observed failed sample (bottom, left) with the corresponding simulation (top, right)

thickness of the plate, and $t_{\text {neck }}$ the neck thickness, assume a biaxial stretch, $\varepsilon_{1}=\varepsilon_{2}$, where $\varepsilon_{1}, \varepsilon_{2}$ are strains in the corresponding directions. Then, since plastic deformation is volume preserving and the elastic strains are very small, we have

$$
\left(1+\varepsilon_{1}\right)^{2}\left(1+\varepsilon_{3}\right)=1, \quad \varepsilon_{1}=\sqrt{\frac{1}{1+\varepsilon_{3}}}-1 .
$$

The effective plastic deformation can now be estimated using,

$\bar{\varepsilon}_{p}=\sqrt{\frac{2}{3}\left(2 \varepsilon_{1}^{2}+\varepsilon_{3}^{2}\right)}$.

Figure 22 shows the neck and pre-neck effective plastic strains for the indicated samples. Excluding the two anomalous cases, the average effective plastic strain just prior to necking and hence failure is about $0.59 \approx$ 0.60 which we have used to simulate the sample failure as discussed above.
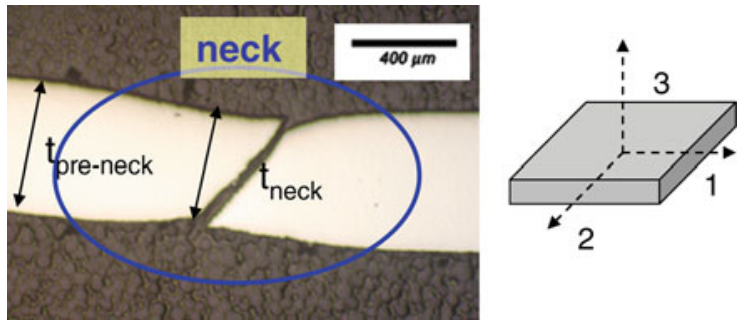

Fig. 21 The neck region, and pre-neck and neck thicknesses used to establish a failure criterion (left); and coordinates used to define in-plane strains

\section{Summary and conclusions}

In this paper the fracturing of impulsively loaded monolithic (DH-36) steel and bilayer steel-polyurea plates is studied using numerical and experimental methods. Using optical and scanning electron microscopes, the microstructureal evolution of some of the failed samples is examined in some detail, focusing 


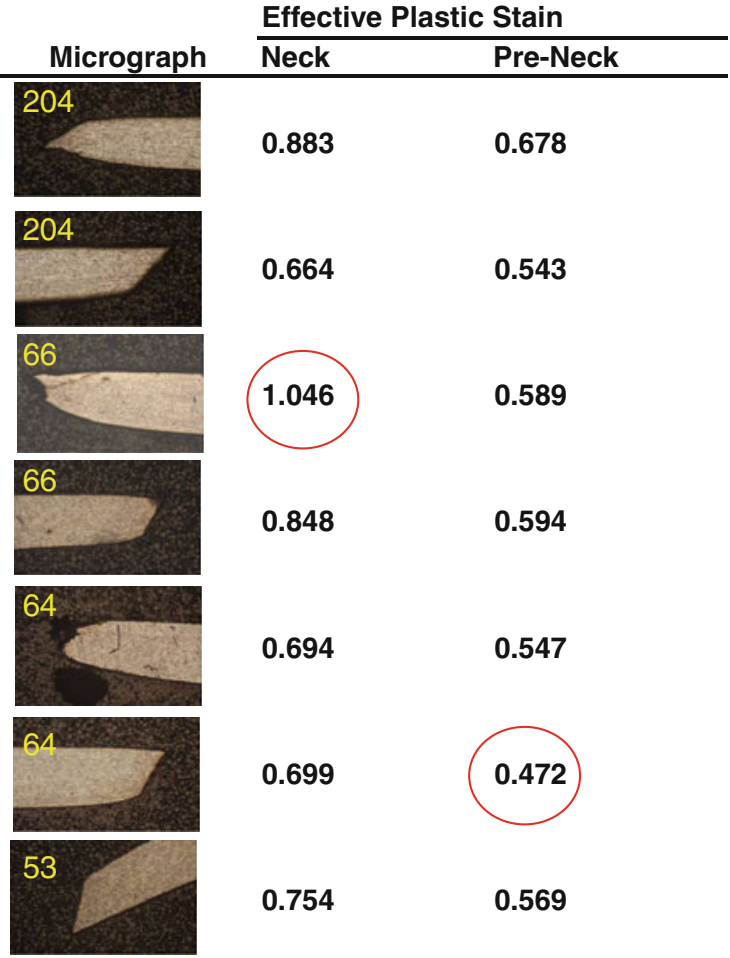

Fig. 22 Micrographs of the necked region for indicated samples, and the corresponding neck and pre-neck thicknesses. Excluding two anomalous cases ( circled), the average pre-neck effective plastic strain is about 0.59

on the fracture and necking patterns, in an effort to understand the underpinning mechanisms of failure. Highly dimpled fracture surfaces indicate ductile fracturing through void nucleation, growth, and coalescence. The examined samples show no sign of shearbanding or significant microstructural changes. Finite-element models are developed based on the micro-scale examination of the failed samples using the commercially available finite-element code LSDYNA. For the numerical simulations, we have used a physics-based and experimentally-supported temperature- and rate-sensitive constitutive model for this steel. This constitutive model is implemented into the finiteelement code. The finite-element models are capable of predicting the fracturing and void growth. The numerical simulations also reveal that the failure of the bare plates initiates at the back face and propagates toward the front face until the sample is fails completely. Moreover, the primary voids that are present near the back face have a significantly greater growth rate compared to the voids near the front face. In addition, a set of simulations is performed to study the effect of polyurea coating on the fracture resistance of the steel plates. These simulations reveal that the presence of a polyurea layer either on the front face or on the back face retards the neck development. However, when polyurea is on the back face, it provides a local enhancement and retards the failure initiation such that the failure initiates from the front face. Based on the examination of necking and fracturing of several samples, a fracture criterion was produced for this material. It appears that, when the effective plastic strain reaches a value of about 0.6 , ductile fracturing follows almost immediately thereafter. Using this failure criterion, the fracturing of a bare steel sample was simulated. Comparison with an experimentally observed failed sample shows remarkably good correlation.

Acknowledgment This work has been supported by the ONR (MURI) grant N000140210666 and ONR grant N00014-06-10340 to the University of California, San Diego, with Dr. Roshdy G. Barsoum as program manager.

Open Access This article is distributed under the terms of the Creative Commons Attribution Noncommercial License which permits any noncommercial use, distribution, and reproduction in any medium, provided the original author(s) and source are credited.

\section{References}

Amini MR, Isaacs JB, Nemat-Nasser S (2010a) Investigation of effect of polyurea on response and failure of steel plates in direct pressure-pulse experiments. Mech Mater (in press)

Amini MR, Simon J, Nemat-Nasser S (2010b) Numerical modeling of effect of polyurea on response and failure of steel plates to impulsive loads in direct pressure-pulse experiments. Mech Mater (in press)

Amirkhizi AV, Isaacs J, McGee J, Nemat-Nasser S (2006) An experimentally-based viscoelastic constitutive model for polyurea, including pressure and temperature effects. Philos Mag Lett 86(36):5847-5866

Bandstra JP, Koss DA (2004) A simulation of growth and coalescence of voids during ductile fracture. Mater Sci Eng 15:399-403

Bandstra JP, Goto DM, Koss DA (1998) Ductile failure as a result of a void-sheet instability: experiment and computational modeling. Mater Sci Eng 249:46-54

Cox TB, Low JR (1974) An investigation of the plastic fracture of AISI 4340 and 18 Nickel-200 grade maraging steels. Mater Trans 5:1457-1470

Curran DR, Seaman L, Shockey D A (1987) Dynamic failure of solids. Phys Rep 147:253-388

Garrison WM, Moody NR (1987) Ductile fracture. J Phys Chem Solids 48:1035-1074

Hammi Y, Horstemeyer MF (2007) A physically motivated anisotropic tensorial representation of damage with sepa- 
rate functions for void nucleation, growth and coalescence. Int J Plast 23:1641-1678

Horstemeyer MF, Gokhale AM (1999) Void-crack nucleation model for ductile metals. Int J Solids Struc 36:5029-5055

LS-DYNA (1998) Theory manual. LSTC, Livermore

McClintock FA (1968) A criterion of ductile fracture by the growth of holes. J Appl Mech 35:363-371

McVeigha C, Vernerey F, Liu WK, Morana B, Olson G (2007) An interactive microvoid shear localization mechanism in high strength steels. J Mech Phys Solids 55:224-225

Nemat-Nasser S, Guo WG (2003) Thermomechanical response of DH-36 structural steel over a wide range of strain rates and temperatures. Mech Mater 35:1023-1047
Rice JR (1976) The localization of plastic deformation. In: Koiter WT (ed) Proceedings of the 14th international congress on theoretical and applied mechanics, vol 1. North-Holland Publishing Co, Delft, pp 207-220

Rice JR, Tracey DM (1969) On the enlargement of voids in triaxial stress fields. J Mech Phys Solids 17:201-217

Tvergaard V, Hutchinson JW (2002) Two mechanisms of ductile fracture: void by void growth versus multiple void interaction. Int J Solids Struc 39:3581-3597

Xue Z, Hutchinson JW (2007) Neck retardation and enhanced energy absorption in metal-elastomer bilayers. Mech Mater 39:473-487 